\title{
INFLUÊNCIA DA LUMINOSIDADE NA PRODUÇÃO DE CAROTENOIDES POR Sporidiobolus pararoseus
}

\author{
C. M. BORBA ${ }^{1}$; C. C. MORAES ${ }^{2}$ J. F. M. BURKERT ${ }^{1}$ \\ ${ }^{1}$ Universidade Federal do Rio Grande - Escola de Química e Alimentos \\ 2Universidade Federal do Pampa - Curso de Engenharia de Alimentos \\ E-mail para contato: carinamolinsborba@yahoo.com.br
}

\begin{abstract}
RESUMO-Carotenoides estão amplamente distribuídos na natureza e apresentam grande importância para a indústria de alimentos. Diferentes fatores podem interferir na produtividade de carotenoides por via biotecnológica, entre eles a luminosidade. Para estudar essa influência foram realizados cultivos de $S$. pararoseus, com presença e ausência de luz, em meio composto por melaço (40 g/L) e água de maceração de milho $(6,5 \mathrm{~g} / \mathrm{L})$, a $180 \mathrm{rpm}, 25^{\circ} \mathrm{C}$ por $168 \mathrm{~h}$, sendo acompanhados $\mathrm{pH}$, biomassa, carotenoides e açúcares. As análises foram realizadas em duplicata e as médias avaliadas por teste t. A luminosidade não influenciou significativamente $(\mathrm{p}>0,05)$ no processo, onde o $\mathrm{pH}$ dos meios de produção variaram entre 6,0 e 4,4, alcançando os pontos máximos de biomassa de 6,31 e 6,60 g/L, e produção de carotenoides de 3495,0 $\mu \mathrm{g} / \mathrm{L}(553,0 \mu \mathrm{g} / \mathrm{g})$ e 4085,6 $\mu \mathrm{g} / \mathrm{L}(617,7 \mu \mathrm{g} / \mathrm{g})$, respectivamente, para presença e ausência de luz. As produtividades em biomassa e produto $0,06 \mathrm{~g} / \mathrm{L} . \mathrm{h}$ e $40,1 \mu \mathrm{g} / \mathrm{L} . \mathrm{h}$ (com luz) e $0,07 \mathrm{~g} / \mathrm{L} . \mathrm{h}$ e $52,6 \mu \mathrm{g} / \mathrm{L} . \mathrm{h}$ (sem luz) também não apresentaram diferença estatística (p>0,05).
\end{abstract}

\section{INTRODUÇÃO}

Os corantes naturais denominados de carotenoides estão amplamente distribuídos na natureza, apresentando papel de destaque na fotossíntese e fotoproteção de sistemas vegetais e como precursores de vitamina A nos seres humanos. Além de funções nos sistemas biológicos, os carotenoides apresentam também grande importância para a indústria farmacêutica na elaboração de cosméticos e como aditivo alimentar na indústria de alimentos (Damoran, et al. 2010).

Apesar de se destacarem por seu papel como pigmentos e antioxidantes, os carotenoides apresentam outras importantes funções, como por exemplo, precursores de aromas além de propriedades antioxidantes, sendo conhecidos por reagirem com o oxigênio singleto, que constitui uma forma altamente reativa do oxigênio molecular (Ambrósio, et al. 2006; Uenojo, et al. 2007; Barbosa, 2010; Cipolatti, 2012).

Os corantes sintéticos apresentam menor custo e maior estabilidade química, porém pesquisadores e consumidores da área de alimentos preocupam-se com sua natureza tóxica. Uma alternativa para sua substituição é a utilização de pigmentos naturais produzidos por algas (Bocanegra et al., 2004; Reis, 2012), bactérias (Gu et al. 2008) e leveduras como as do gênero Sporidiobolus (Valduga, et al. 2009; Otero, 2011). 
Do ponto de vista químico, os carotenoides possuem estrutura básica formada por unidades de isopreno ligadas covalentemente, criando uma molécula simétrica com 40 carbonos. Sua cadeia altamente insaturada torna esses pigmentos susceptíveis a isomeração e oxidação.

Fatores como calor, acidez e luz podem promover a isomeração de carotenoides trans (forma usual) para conformação cis. Esses fatores podem ainda, dependendo da concentração de oxigênio presente no meio, estimular a degradação oxidativa, sendo que tanto o processo de isomeração quanto a oxidação levam a perda de cor e também atividade provitamina A (Damoran, et al. 2010, Rodriguez-Amaya, 2001).

Em vista disso o presente trabalho teve como objetivo o estudo da influência da luminosidade na produção de carotenoides por Sporidiobolus pararoseus, realizando cultivos com presença e ausência de luz.

\section{METODOLOGIA}

\subsection{REATIVAÇÃO DAS CULTURAS MICROBIANAS}

Foi utilizada a levedura carotenogênica Sporidiobolus pararoseus isolada de amostras ambientais (Otero, 2011).

Para a reativação, foram realizados repiques a partir das culturas estoques em meio extrato de malte e levedura (YM) composto por $3 \mathrm{~g} / \mathrm{L}$ de extrato de levedura, $3 \mathrm{~g} / \mathrm{L}$ de extrato de malte, $5 \mathrm{~g} / \mathrm{L}$ de peptona, $10 \mathrm{~g} / \mathrm{L}$ de glicose modificado segundo Parajó et al. (1998) pela adição de $0,2 \mathrm{~g} / \mathrm{L}$ de $\mathrm{KNO}_{3}$, por $48 \mathrm{~h}$ a $25^{\circ} \mathrm{C}$. Após foi realizada uma ressuspensão celular em 1 $\mathrm{mL}$ de água peptonada $(0,1 \%)$ e adicionada em $9 \mathrm{~mL}$ de caldo $\mathrm{YM}$ modificado, sendo incubados nas mesmas condições descritas anteriormente.

\subsection{PREPARO DO INÓCULO}

O inóculo foi preparado em frascos agitados de $250 \mathrm{~mL}$ contendo $90 \mathrm{~mL}$ de caldo YM modificado adicionado de $10 \mathrm{~mL}$ de cultivo oriundo da reativação, sendo incubado a $150 \mathrm{rpm}$, $25^{\circ} \mathrm{C}$ por $48 \mathrm{~h}$, ou tempo necessário para concentração celular atingir $1 \times 10^{7}$ células $/ \mathrm{mL}$, contadas através de câmara de Neubauer.

\subsection{CULTIVO}

O meio de cultura utilizado foi otimizado por Machado (2013), composto por melaço de cana de açúcar $(40 \mathrm{~g} / \mathrm{L})$ e água de maceração de milho $(6,5 \mathrm{~g} / \mathrm{L})$, pré-tratado com ácido sulfúrico (Roukas, 1998). 
Os ensaios realizados em erlenmeyer de $500 \mathrm{~mL}$ com $225 \mathrm{~mL}$ do meio, com $\mathrm{pH}$ inicial de 6,0, acrescidos de $10 \%$ de inoculo, sendo as condições operacionais do processo $25^{\circ} \mathrm{C}, 180$ rpm por 168 h (Silva, 2009). Para os ensaios na ausência de luminosidade, os erlenmeyer foram recobertos com papel alumínio.

Amostras foram retiradas em intervalos de $24 \mathrm{~h}$ até o término do processo (168h), a fim de acompanhar biomassa, $\mathrm{pH}$, açúcares e carotenoides totais. Para isso a biomassa foi recuperada por centrifugação (centrífuga Cientec CT-6000R) a $1745 \times$ g por 10 min e o sedimento lavado com água destilada. O sobrenadante foi utilizado para medição de $\mathrm{pH}$ e quantificação dos açúcares. Após, a biomassa foi submetida à secagem por $48 \mathrm{~h}$ a $35^{\circ} \mathrm{C}$ (Fonseca et al., 2011), sendo macerada em um grau e passada em peneira com mesh 115 conforme padronizada por Cipolatti (2012) e posteriormente submetida ao congelamento a $18^{\circ} \mathrm{C}$ por $48 \mathrm{~h}$ (Moraes et al., 2010).

\subsection{ACOMPANHAMENTO DE BIOMASSA, pH E AÇÚCARES}

A concentração de biomassa ao longo do processo foi estimada por leitura de absorbância a $620 \mathrm{~nm}$, através de uma curva padrão de biomassa (Choi e Park , 2003), já a determinação do $\mathrm{pH}$ foi realizada através da leitura da amostra em um potenciômetro.

Para acompanhamento de açúcares redutores totais foi utilizado o método do Ácido 3,5dinitrosalicílico (Miller, 1959), com uma curva padrão de glicose. As amostras foram previamente submetidas a uma hidrólise.

\subsection{ROMPIMENTO CELULAR E OBTENÇÃO DO EXTRATO CAROTENOGÊNICO}

O processo de rompimento celular se deu por técnica química aplicando-se dimetil sulfóxido (DMSO), seguindo a metodologia adaptada de Michelon, et al. (2012). Em tubos contendo $0,05 \mathrm{~g}$ de biomassa foi adicionado $2 \mathrm{~mL}$ de DMSO a $55^{\circ} \mathrm{C}$ sendo agitado em vórtex por 1 minuto e posteriormente deixado em repouso por $1 \mathrm{~h}$.

Após a ruptura foram adicionados $6 \mathrm{~mL}$ de acetona, a fim de promover a extração dos carotenoides. A amostra será centrifugada a $1745 \mathrm{xg}$ por $10 \mathrm{~min}$, a fase solvente separada e o procedimento de ruptura repetido até descoloração total das célula. Aos sobrenadantes serão adicionados $10 \mathrm{~mL}$ de solução de $\mathrm{NaCl} 20 \%(\mathrm{p} / \mathrm{v})$ e $10 \mathrm{~mL}$ de éter de petróleo. Após a formação de duas fases foi coletado a fase apolar sendo filtrada com sulfato de sódio $\left(\mathrm{Na}_{2} \mathrm{SO}_{4}\right)$, dando origem aos extratos carotenogênicos (Michelon, et al. 2012).

\subsection{DETERMINAÇÃO DE CAROTENOIDES TOTAIS}

A determinação da concentração de carotenoides totais nos extratos foi realizada em espectrofotômetro através do valor médio da máxima absorbância a $448 \mathrm{~nm}$, utilizando a 
Equação 1, e será expresso em termos de seu carotenoide majoritário ( $\beta$-caroteno em éter de petróleo com absortividade especifica de $=2592$ ) de acordo com Davies (1976).

$$
C T=\frac{A * V * 10^{6}}{A_{1}^{1 \%} m^{*} 100 * m_{\text {amostra }}}
$$

Onde:

$\mathrm{CT}=$ concentração específica de carotenoides de totais $(\mu \mathrm{g} / \mathrm{g}) ; \mathrm{A}=$ absorvância; $\mathrm{V}=$ volume $(\mathrm{mL}) ; \mathrm{m}_{\text {amostra }}=$ massa celular seca $(\mathrm{g}) ; \mathrm{A}_{1 \mathrm{~cm}}^{1 \%}=$ absortividade específica.

Para o cálculo da produção volumétrica de carotenoides totais $(\mu \mathrm{g} / \mathrm{L})$ foi realizada uma conversão de unidades utilizando o resultado de contração e carotenoides toais $(\mu \mathrm{g} / \mathrm{g})$ e de concentração de biomassa (g/L).

\subsection{ANÁLISE ESTATÍSTICA}

As análises foram realizadas em duplicatas e avaliadas através de teste $\mathrm{t}$ com confiança de $95 \%$, através de software estatístico.

\section{RESULTADOS E DISCUSSÃO}

Na Figura 1 são apresentados os valores de biomassa, açúcares, $\mathrm{pH}$ e carotenoides observados durante o acompanhamento do processo. E na Tabela 1 são apresentados as médias dos parâmetros cinéticos máximos (96 h).

No parâmetro biomassa os maiores valores obtidos foram $6,60 \mathrm{~g} / \mathrm{L}$ para a produção em presença de luz e 6,31 g/L para a produção com ausência de luz. As médias quando comparadas por teste $t$, foram consideradas estatisticamente iguais ( $p>0,05)$. Não houve também diferença estatística entre a produtividade em biomassa na presença ou ausência de luz (Tabela 1).

A produção máxima de carotenoides volumétricos foi de 3495,0 $\mu \mathrm{g} / \mathrm{L}$ e 4085,6 $\mu \mathrm{g} / \mathrm{L}$, respectivamente, para presença e ausência de luz, ambas obtidas em $96 \mathrm{~h}$ de produção. A análise dos dados demostrou não haver diferença estatística $(p>0,05)$ estres as duas médias assim como na produtividade em carotenoides.

$\mathrm{O}$ pH é um dos mais significativos parâmetros na bioprodução de compostos, por influenciar o crescimento do micro-organismo e formação de produto. Segundo Valduga, et al. (2009) é natural que durante a síntese de carotenoides ocorram mudanças de $\mathrm{pH}$, sendo essas mais intensas nas primeiras $72 \mathrm{~h}$, com posterior elevação desse $\mathrm{pH}$ durante a fase intensa de carotenogênese.

No presente estudo o $\mathrm{pH}$ sofreu maior variação nas primeiras $48 \mathrm{~h}$ nas duas condições. $\mathrm{O}$ pH nos pontos de máxima produção foram de 4,4 e 4,8 (Tabela 1). 


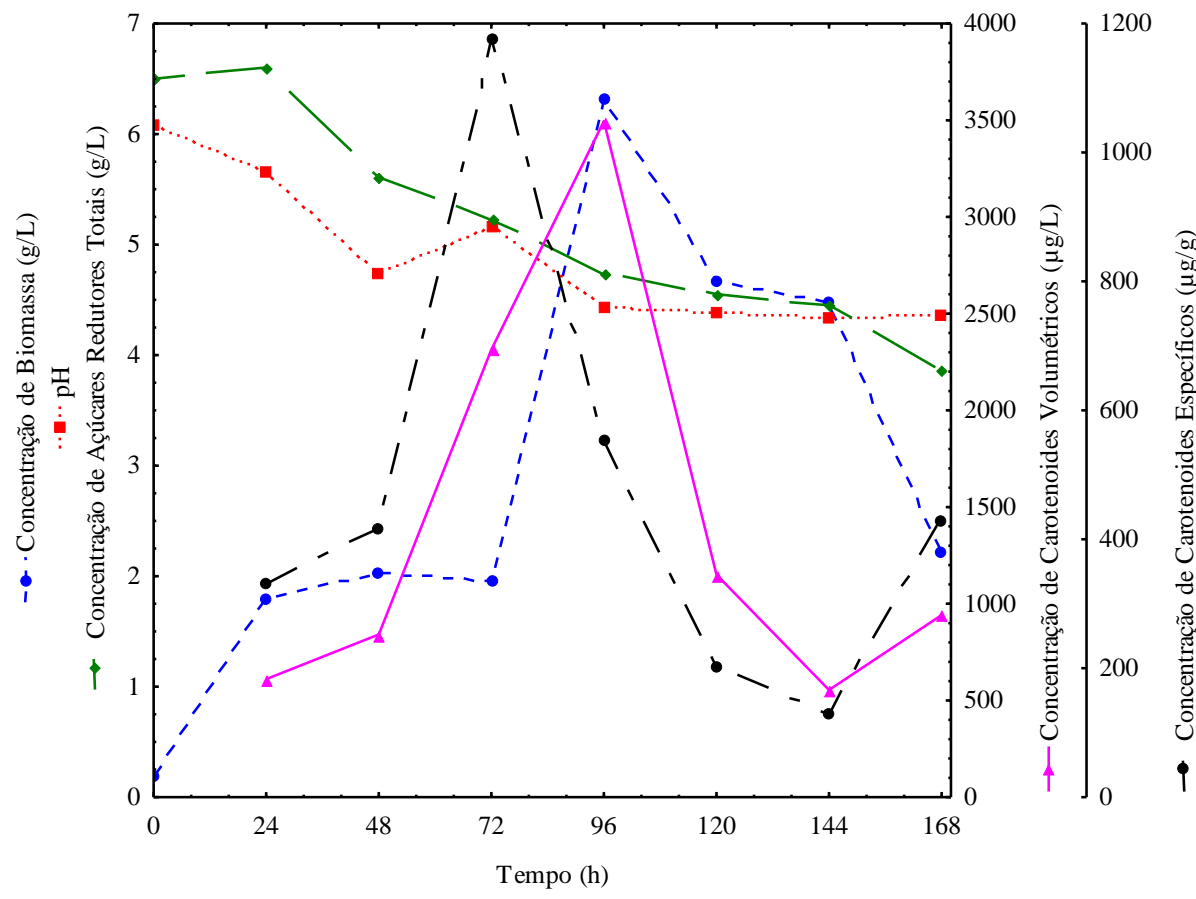

(a)

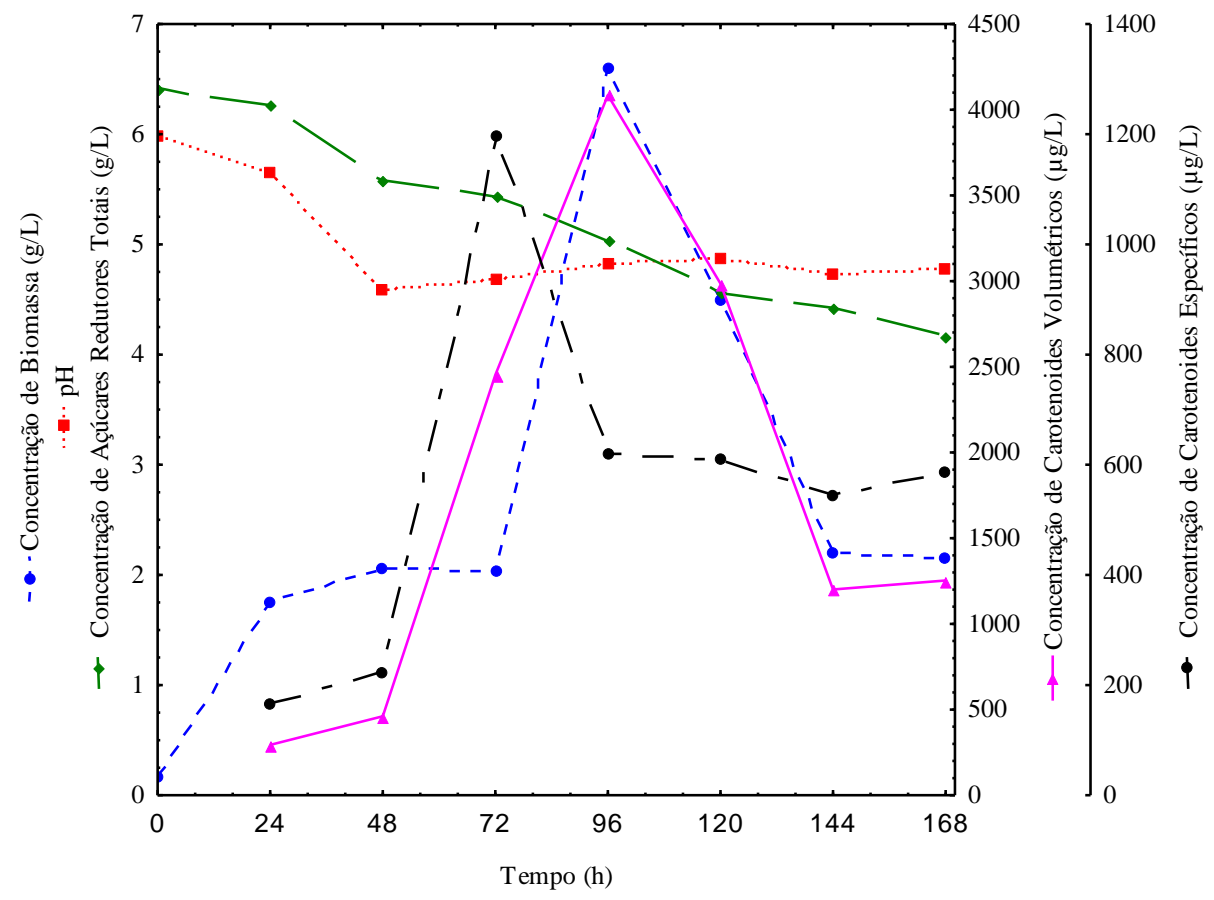

(b)

Figura 1 - Cinética da produção de carotenoides por Sporidiobolus pararoseus na presença (a) e ausência (b) de luz. 
Tabela 1- Médias dos parâmetros cinéticos da produção de carotenoides por Sporidiobolus pararoseus na presença e ausência de luz.

\begin{tabular}{cccccc}
\hline Luminosidade & $\begin{array}{c}\text { Biomassa } \\
(\mathrm{g} / \mathrm{L})\end{array}$ & $\begin{array}{c}\text { Carotenoides } \\
\text { Volumétricos } \\
(\boldsymbol{\mu g} / \mathrm{L})\end{array}$ & $\mathbf{p H}$ & Px $(\mathrm{g} / \mathrm{L} . \mathbf{h})$ & Pc $(\boldsymbol{\mu g} / \mathbf{L} . \mathbf{h})$ \\
\hline Presente & $6,31^{\mathrm{a}}$ & $3495,0^{\mathrm{b}}$ & $4,4^{\mathrm{c}}$ & $0,06^{\mathrm{d}}$ & $40,1^{\mathrm{e}}$ \\
Ausente & $6,60^{\mathrm{a}}$ & $4085,6^{\mathrm{b}}$ & $4,8^{\mathrm{c}}$ & $0,07^{\mathrm{d}}$ & $52,6^{\mathrm{e}}$ \\
\hline
\end{tabular}

*Letras iguais na mesma coluna demostram resultados estatisticamente iguais $(\mathrm{p}>0,05)$.

No presente trabalho não foi observada a interferência da luminosidade sobre a produção de carotenoides, porém segundo Boshale (2004), a produção e acumulação de carotenoides em algas, fungos e bactérias é positivamente afetada pela irradiação de luz branca. Sendo que o aumento na produção volumétrica de carotenoides, geralmente está associado ao desenvolvimento do micro-organismo, além de sua interferência na ação e produção de enzimas necessárias para a carotenogênese. Assim, o efeito da luz sobre o desenvolvimento dos micro-organismos desempenha papel importante para se estabelecer a função da luz branca como estimulante da produção de carotenoides.

Zhang et al. (2014) avaliou a interferência de três condições de irradiação luminosa sobre a produção de biomassa, carotenoides e lipídios por Rhodotorula glutinis. A três condições eram ausência de luz, 2 lâmpadas LED e 3 lâmpadas LED de $800 \mu \mathrm{mol} / \mathrm{m}^{2}$ cada. As irradiação luminosa aumentou significativamente o concentração de biomassa no processo, apresentando maior valor $(17,7 \mathrm{~g} / \mathrm{L})$ com o uso de 3 LED's. Nessa mesma condição foram encontradas as maiores concentrações de carotenoides, $2,6 \mathrm{mg} / \mathrm{L}$, mais que o dobro do obtido na ausência de irradiação luminosa. Muitas leveduras não fotossintetizantes e bactérias utilizam os carotenoides como proteção quando cultivadas na presença de luz. Assim a aplicação irradiação durante o cultivo pode não só aumentar a concentração de biomassa e carotenoides, como reduzir o tempo de cultivo.

Se faz necessário o estudo da utilização da luz nas diferentes fases do desenvolvimento microbiano, o tipo de luz empregada e o perfil de carotenoides desejados, visto que a estrutura química desses corantes podem ser afetadas pela irradiação, permitindo assim seja possível determinar condições de produção utilizando $S$. pararoseus, que levem a maiores produções de carotenoides, sem perdas em sua coloração e atividade provitamina A.

\section{CONSIDERAÇÕES FINAIS}

A luminosidade não influenciou significativamente $(\mathrm{p}>0,05)$ o processo. $\mathrm{O} \mathrm{pH}$ dos meios de produção variaram entre 6,0 e 4,4, alcançando os pontos máximos de biomassa de 6,31 e 6,60 g/L, e produção de carotenoides volumétricos de 3495,0 e 4085,6 $\mu \mathrm{g} / \mathrm{L}$, 
respectivamente, para presença e ausência de luz e produtividade em biomassa e produto 0,06 g/L.h e 40,1 $\mu$ g/L.h (com luz) e 0,07 g/L.h e 52,6 $\mu \mathrm{g} / \mathrm{L} . \mathrm{h}$ (sem luz).

\section{REFERÊNCIAS BIBLIOGRÁFICAS}

AMBRÓSIO, C. L.; CAMPO, F. de A. C. e S.; FARO, Z. P. Carotenoides como alternativa contra a hipovitaminose A. Rev. Nutr., n. 19, v. 2, p. 233-243, 2005.

BOCANEGRA, A. R. D.; LEGARRETA, I. G.; JERONIMO, F. M. Influence of environmental and nutritional factors in the production of astaxanthin from Haematococcus pluvialis. Bioresource Technol., v. 92, p. 209-214, 2004.

BARBOSA, M. M. Obtenção de carotenoides de flavonoides a partir do bagaço do pedúnculo do caju por maceração enzimática e prensagem. 2010. 120 f. Dissertação (Mestrado em Engenharia Química) - Universidade Federal do Ceará, Fortaleza, 2010.

BHOSALE, P. Environmental and cultural stimulants in the production of carotenoids from microorganisms. Appl. Microbiol. Biot., v.63 p.351-361, 2004.

CIPOLATTI, E. P. Obtenção de carotenoides microbianos com atividade antioxidante a partir de coprodutos agroindustriais. 2012. 120f. Dissertação (Mestrado em Engenharia e Ciência de Alimentos) - Universidade Federal do Rio Grande, Rio Grande, 2012.

CHOI, M.H.; PARK, Y.H. Production of yeast biomass using waste Chinese cabbage. Biomass Bioenerg, v. 25, p. 221-226, 2003.

DAMODARAM, S.; PARKIN, K. L.; FENNEMA, O. R. Química de Alimentos de Fennema. Porto Alegre: Artmed, 2010.

DAVIES, B. H. Chemical Biochemistry Plant Pigments. New York: Academic Press, 1976.

FONSECA, R. A. S.; RAFAEL, R. S.; KALIL, S. J.; BURKERT, A. V.; BURKERT, J. F. M. Different cell disruption methods for astaxanthin recovery by Phaffia rhodozyma. Afri. J. Biotechnol., v. 10, n. 7, p. 1165-1171, 2011.

GU, Z.; CHEN, D.; HAN, Y; CHEN, Z.; GU, F. Optimization of carotenoids extraction from Rhodobcter sphaeroides. LWT, v. 41, p. 1082-1088, 2008.

MACHADO, W. R. C. Otimização da produção de carotenoids por Sporodiobolos pararoseus e influência de pré tratamentos nos meios de cultivos agroindustriais. $2013.90 \mathrm{f}$. Dissertação (Mestrado em Engenharia e Ciência de Alimentos - Universidade Federal do Rio Grande, Rio Grande, 2013.

MICHELON, M. BORBA, T. de M.; RAFAEL, R. da S.; BURKERT, C. A. V.; BURKERT, J. F. de M.; Extration of carotenoids from Phaffia rhodozyma: a comparison between diferent techniques of cell disruption. Food, Sci, Biotechnol. v.1, p. 1-8, 2012. 
MILLER, G. L Use of dinitrosalicylic acid reagent for determination of reducing sugar. Anal. Chem., v. 31, p. 426-428, 1959.

MORAES, C. C.; BURKERT, J. F. M.; KALIL, S. J. C-phycocyanin extraction process for large-scale use. J. Food Biochem., v. 34, p. 133-148, 2010.

OTERO, D. M. Bioprospecão de leveduras silvestres produtoras de carotenoides. $2011.76 \mathrm{f}$. Dissertação (Mestrado em Engenharia e Ciência de Alimentos) - Universidade Feradal do Rio Grande, Rio Grande, 2011.

PARAJÓ, J. C. V. S., VÁZQUEZ, M. Optimization of carotenoid production by Phaffia rhodozyma cell grown on xylose. Process Biochem., v. 33, n. 2, p. 181-187, 1998.

RODRIGUEZ-AMAYA, D. B. A guide to carotenoid analysis in food. New York: One Thomas Circle, 2001.

REIS, D. F. Crescimento celular e produção de carotenoides pela microalga Haematococcus pluvialis. 2012. 81 f. Dissertação. (Mestrado em Engenharia e Ciência de Alimentos) Universidade Federal do Rio Grande, Rio Grande, 2012.

ROUKAS, T. Preatreatment of beet molasses to increase pillilan production, Process Biochem., v. 33, n. 8, p. 805-810, 1998.

SILVA, D. A. Maximização da produção de astaxantina por Phaffia rhodozyma utilizando água de parboilização do arroz. 2009. 93f. Dissertação (Mestrado em Engenharia e Ciência de Alimentos) - Universidade Federal do Rio Grande, Rio Grande, 2009.

UENOJO, M., MARÓSTICA Jr,, M. R.; PASTORE, G. M. Carotenoides: propriedades, aplicações e biotrasnformação para formação de compostos de aroma. Quim. Nova, v. 30, n. 3, p. 616-622, 2007.

VALDUGA, E.; TATSCH, P; O;; TIGGEMANN, L. TREICHEL, H.; TONIAZZO, G. ZENI, J. DI LUCCIO, M.; Produção de carotenoides: microrganismos como fonte de pigmentos naturais. Quim. Nova, v. 32, n. 9, p.2429-2436, 2009.

ZHANG, Z. TAN, T. Lipid and carotenoid production by Rhodotorula glutinis under irradiation/high-temperature and dark/low-temperature cultivation. Bioresource Technol., v. 157, p. 149-153, 2014. 